\title{
Thyroid hormones suppress FOXM1 expression to reduce liver cancer progression
}

\author{
CHENG-HENG WU ${ }^{1}$, CHAU-TING YEH $^{2}$ and KWANG-HUEI LIN ${ }^{1-3}$ \\ ${ }^{1}$ Department of Biochemistry, College of Medicine, Chang Gung University; \\ ${ }^{2}$ Liver Research Center, Chang Gung Memorial Hospital; ${ }^{3}$ Research Center for Chinese Herbal Medicine, \\ College of Human Ecology, Chang Gung University of Science and Technology, Taoyuan 333, Taiwan, R.O.C.
}

Received October 1, 2019; Accepted June 18, 2020

DOI: $10.3892 /$ or.2020.7716

\begin{abstract}
Thyroid hormones (TH) are multifunctional mediators that fine-tune several physiological processes, including metabolic rate, digestive function and tissue development via interactions with type II nuclear thyroid hormone receptors (TR). Upon binding of TH, TRs interact specifically with thyroid hormone response elements of target gene promoter regions to regulate their transcription. Earlier studies suggested a correlation between aberrant TR regulation and hepatocellular carcinoma (HCC). THs are involved in a crosstalk between hepatoma and stromal cells, and disruption of TH signaling is associated with tumorigenesis. Previous cDNA microarray analysis of target gene expression following $\mathrm{T}_{3}$ treatment of wild-type TR-expressing hepatoma cells led to the identification of forkhead box M1 (FOXM1) as a factor negatively regulated by $\mathrm{T}_{3}$ and associated with poor prognosis in several cancer types. Increased FOXM1 expression during late stages of HCC was associated with poorer overall and recurrence-free survival in patients with HCC. However, the specific mechanisms underlying FOXM1 activity in liver cancer progression remain to be elucidated. Experiments from the present study showed that TH/TR signaling suppresses FOXM1 mRNA and protein expression. Depletion of FOXM1 induced inhibition of the cell growth rate and a decline in oncogenic cyclin D1, cyclin E and CDK2 expression. Conversely, overexpression of FOXM1 enhanced cell proliferation and expression of oncogenic factors, which was decreased upon FOXM1 depletion. Re-expression of FOXM1 partially rescued suppression of cell proliferation induced by $\mathrm{T}_{3}$. Collectively, the present findings suggest that TH/TR participates in HCC progression via modulation of FOXM1 expression.
\end{abstract}

Correspondence to: Professor Kwang-Huei Lin, Department of Biochemistry, College of Medicine, Chang Gung University, 259 Wenhua First Road, Guishan, Taoyuan 333, Taiwan, R.O.C.

E-mail:khlin@mail.cgu.edu.tw

Key words: forkhead box MI, thyroid hormone receptor, thyroid hormone, hepatocellular carcinoma, prognosis, proliferation

\section{Introduction}

Thyroid hormones (TH) are multifunctional mediators that fine-tune several physiological processes, including metabolic rate, digestive function and tissue development $(1,2) . \mathrm{T}_{4}$, the major $\mathrm{TH}$ secreted into the bloodstream by the thyroid gland, is converted to its active form, $\mathrm{T}_{3}$, by type I and II deiodinases (D1 and D2) that vary among tissues, resulting in tissue-specific distribution of circulating $\mathrm{T}_{3}$ with the capability to bind nuclear thyroid hormone receptors (TR) (3). Upon binding of TH, TRs interact specifically with thyroid hormone response elements (TRE) of target gene promoter regions to regulate their transcription $(4,5)$.

TRs are type II nuclear receptors encoded by two separate genes, THRA (NR1A1) and THRB (NR1A2). THRA encodes one functional $\mathrm{T}_{3}$-binding $\mathrm{TR} \alpha 1$ while $\mathrm{TR} \alpha 2$ and $\mathrm{TR} \alpha 3$ have been identified as splice variants with no $\mathrm{T}_{3}$ binding ability. TR $\Delta \alpha 1$ and TR $\Delta \alpha 2$ are truncated variants without DNA binding domains but retain $\mathrm{T}_{3}$ binding ability and compete with other TRs. THRB genes encode three functional $\mathrm{T}_{3}$-binding $\mathrm{TR} \beta$ isoforms, specifically, $\beta 1, \beta 2$ and $\beta 3$ (3). Truncated TR $\Delta \beta 3$ lacks the DNA binding domain but retains $\mathrm{T}_{3}$ binding activity and acts as a dominant-negative antagonist, similar to TR $\Delta \alpha 1$ and TR $\Delta \alpha 2$ (6-9). Several studies to date have reported aberrant expression and/or somatic mutations of TR in human cancers (3,10-18), including hepatocellular carcinoma (HCC) (19-28).

$\mathrm{HCC}$ is the major histological subtype of primary liver malignancy and one of the major causes of tumor-related mortalities worldwide (29). Liver cirrhosis is the premonitory symptom of HCC, with the majority of cases developing from cirrhotic livers (30).

In 1986, v-erbA, a mutant form of TR devoid of ligand binding ability borne by the avian erythroblastosis virus causing erythroleukemia was identified and subsequently shown to play a role in HCC in transgenic mice $(4,31)$. Mutated or truncated forms of $\operatorname{TR} \alpha$ and $\operatorname{TR} \beta$ are expressed at high frequencies in human HCC (32-36). These mutant TRs display loss of transcriptional activity, along with defects in release and binding of ligand-driven corepressor, and further act as dominant-negative forms, highlighting an association between aberrant TR regulation and HCC (1). 
In rat models of HCC generated by a combination of diethylnitrosamine (DEN) and partial hepatectomy, 2-acetylaminofluorene or a High-fat choline-methionine-deficient diet, $\mathrm{T}_{3} / \mathrm{TR}$ signaling was shown to suppress carcinogenesis via induction of a preneoplastic hepatocyte differentiation program (2). Disruption of TH signaling promoted tumorigenesis, particularly in HCC (2). Analysis of the genes modulated by $\mathrm{T}_{3} / \mathrm{TR}$ in HCC should therefore facilitate elucidation of the mechanisms underlying HCC progression. Previous cDNA microarrays conducted by our group to evaluate target gene expression following $\mathrm{T}_{3}$ treatment of wild-type $\mathrm{TR}$-expressing hepatoma cells led to the identification of forkhead box M1 (FOXM1), also known as hepatocyte nuclear factor (HNF)-3, HNF-3/fork head homologue-11, membrane palmitoylated protein 2, winged-helix transcription factor or Trident $(37,38)$, as a molecule negatively regulated by $\mathrm{T}_{3}$.

FOXM1 is characterized by the presence of the DNA-binding domain Forkhead/Winged-helix domain (FKH) (39). Earlier cDNA microarray data suggested that FOXM1 is negatively regulated by $\mathrm{T}_{3}$ in a TR $\alpha 1$-overexpressing hepatoma cell line (40). Similar to TR, FOXM1 participated in the cellular developmental pathway and maintenance of homoeostasis by activating multiple target genes regulating DNA damage repair, cell proliferation, cell cycle progression, renewal, differentiation, migration, angiogenesis and survival (41). Deregulation of FOXM1 signaling was shown to trigger malignant transformation (42). The mechanisms underlying signal transduction of FOXM1 contributing to tumor growth have been partially elucidated and appear to involve interplay with PI3K, ERK, epidermal growth factor receptor, estrogen receptor, vascular endothelial growth factor and reactive oxygen species $(37,41,43)$, but require further clarification. Data from the current study indicated that TH/TR-modulated FOXM1 participates in HCC progression via affecting downstream gene expression, further highlighting the biological importance of TH/TR homeostasis.

\section{Materials and methods}

Cell culture and $T_{3}$ depletion. Human hepatoma cell lines J7 (provided by Dr CS Yang, National Taiwan University, Taiwan) (44), Mahlavu, SK-Hep1, HepG2 (American Type Culture Collection) and Huh7 (provided by Dr TY Hsieh, Tri-Service General Hospital, Taiwan) (45) were routinely grown in DMEM (Thermo Fisher Scientific, Inc.) supplemented with 10\% FBS (EMD Millipore), L-glutamine, 1\% penicillin/streptomycin (PS) and non-essential amino acids (NEAAs). HepG2 cell lines stably transfected with TR $\alpha 1$ (HepG2-TR $\alpha 1)$, TR $\beta 1$ (HepG2-TR $\beta 1$ ) or vector control (HepG2-neo) have been previously established in our laboratory (46). To generate $\mathrm{T}_{3}$-depleted FBS (Td-FBS), AG 1-X8 resin (Bio-Rad Laboratories, Inc.) was washed three times with distilled, deionized water (15 min each time), pelleted by brief centrifugation $(6,000 \mathrm{x} \mathrm{g}, 5 \mathrm{~min}$, room temperature) and sterilized by autoclaving. $\mathrm{T}_{3}$ of FBS $(50 \mathrm{ml})$ was depleted by incubationwith $2.2 \mathrm{~g} \mathrm{AG} \mathrm{1-X8} \mathrm{resin} \mathrm{three} \mathrm{times} \mathrm{each} \mathrm{for}$ $5 \mathrm{~h}$ and filtered. Cells were cultured in DMEM with $1 \%$ PS, L-glutamine, NEAAs and 10\% Td-FBS and treated with $0 \mathrm{nM}$ $\mathrm{T}_{3}$ (control group, Neo $\mathrm{T}_{3} 0 \mathrm{nM}$, FOXM1 $\mathrm{T}_{3} 0 \mathrm{nM}$ ) or $10 \mathrm{nM}$ $\mathrm{T}_{3}$ (experimental group, Neo $\mathrm{T}_{3} 10 \mathrm{nM}$, FOXM1 $\mathrm{T}_{3} 10 \mathrm{nM}$ ) for
24 and $48 \mathrm{~h}$ at $37^{\circ} \mathrm{C}$ in a humidified atmosphere of $95 \%$ air and $5 \% \mathrm{CO}_{2}$. The cell lines were authenticated using the Promega StemElite ID system (Promega Corporation), a short tandem repeat-based assay (25).

Establishment of FOXM1 knockdown and overexpression cell lines. FOXM1 short hairpin RNA (shRNA) TRCN0000015544 (shFOXM1\#1; 5'-CCGGGCCCAACAGGAGTCTAATCAAC TCGAGTTGATTAGACTCCTGTTGGGCTTTTT-3') and TRCN0000015547 (shFOXM1\#2; 5'-CCGGCGCCGGAACAT GACCATCAAACTCGAGTTTGATGGTCATGTTCCGGC GTTTTT-3') and pLKO.1-shLuc (control group) were purchased from the RNA interference core laboratory (Academia Sinica, Taipei, Taiwan). A total of $5 \mu \mathrm{g}$ shRNA and $5 \mu \mathrm{g}$ lentiviral package plasmids were co-transfected in 293TN cells (System Biosciences, LLC) cultured in DMEM with $1 \%$ PS, L-glutamine, NEAAs and $10 \%$ FBS using a TurboFect reagent kit (Thermo Fisher Scientific, Inc.) to produce viruses. After $24 \mathrm{~h}$, viral supernatant was collected by centrifugation $(4,000 \mathrm{x} \mathrm{g}, 5 \mathrm{~min}$, room temperature) for infection of $\mathbf{J} 7$ and Mahlavu cell lines as these cell lines expressed lower levels of FOXM1 following viral infection for FOXM1 depletion. $48 \mathrm{~h}$ after infection, cells were transferred to DMEM with $1 \% \mathrm{PS}$, L-glutamine, NEAAs, 10\% FBS and puromycin for selection. After $48 \mathrm{~h}$ of incubation, FOXM1 expression was confirmed via western blotting. The control groups for $\mathbf{J} 7$ and Mahlavu (shluc\#1 and shluc\#2) were established by two independent viral infections of pLKO.1-shLuc. The FOXM1 coding sequence (NM_021953) was cloned into a pcDNA3.1 expression vector (Addgene, Inc.). A total of $5 \mu \mathrm{g}$ FOXM1-pcDNA3.1 (Neo-FOXM1) and $5 \mu \mathrm{g}$ control plamid pcDNA3.1 (Neo) were transfected into SK-Hep1 and Huh7 cells with TurboFect reagent for $24 \mathrm{~h}$. The sequences of primer pairs used for FOXM1 were as follows: Forward, 5'-CGCGGATCCGCGATGAAAACTAGCCCCCGTCGGC-3' and reverse, 5'-CCGGAATTCCGGCTACTGTAGCTCAGG AATAAAC-3'.

Reverse transcription-quantitative PCR (RT-qPCR). Total RNA from HepG2-TR $\alpha 1$, HepG2-TR $\beta 1$ and HepG2-neo cells was purified using TRIzol ${ }^{\circledR}$ reagent (Invitrogen; Thermo Fisher Scientific, Inc.) according to the supplier's protocol and reverse-transcribed into cDNA using a Superscript II kit according to the manufacturer's protocol (Thermo Fisher Scientific, Inc.). The reaction was performed in a $25-\mu 1$ reaction mixture containing $50 \mathrm{nM}$ forward and reverse primers, 1X SYBR Green reaction mix (Applied Biosystems; Thermo Fisher Scientific, Inc.) and $50 \mathrm{ng}$ cDNA template. The following thermocycling conditions were used for the qPCR: Initial denaturation for $10 \mathrm{~min}$ at $95^{\circ} \mathrm{C}$, followed by 40 cycles of $95^{\circ} \mathrm{C}$ for $15 \mathrm{sec}$ and final extension at $60^{\circ} \mathrm{C}$ for $1 \mathrm{~min}$. Fluorescence emitted by SYBR Green was detected on line using a ABI PRISM 7500 sequencer (Applied Biosystems; Thermo Fisher Scientiic, Inc.). Studies have shown that the initial copy number can be quantified during RT-qPCR analysis based on the threshold cycle $(\mathrm{Ct})$. The $\mathrm{Ct}$ is defined as the cycle at which fluorescence is determined to be statistically significant above background. All PCRs were perfomed in duplicate on the same 96-well plate. For quantification of gene expression changes, the $2^{-\Delta \Delta \mathrm{Cq}}$ method (47) was used to calculate relative-fold changes normalized to $18 \mathrm{~S}$ ribosomal RNA expression (18S rRNA) as 
described by the manufacturer (Applied Biosystems; Thermo Fisher Scientific, Inc.). The following primer pairs were used for the qPCR: FOXMI forward, 5'-TCCTCAGCTAGCAGC ACCTTG-3' and reverse, 5'-CCAGGTGTTTAAGCAGCA GA-3' and 18S rRNA forward, 5'-CGAGCCGCCTGGATA CC-3' and reverse, 5'-CCTCAGTTCCGAAAACCAACAA-3'.

Western blot analysis. Total cell lysates of HepG2, J7, Mahlavu, SK-Hep-1 and Huh7-cells were prepared using cell lysis buffer (cat. no. 9803; Cell Signaling Technology, Inc.) and protein concentrations were determined using a Bradford assay kit (Pierce; Thermo Fisher Scientific, Inc.). Western blot experiments were performed as previously described (46). Equal amounts of protein $(60 \mu \mathrm{g} /$ lane $)$ were separated by 8-10\% SDS-PAGE. Separated proteins were transferred to polyvinylidene difluoride membranes and blocked in 5\% milk for $1 \mathrm{~h}$ at room temperature. Following blocking, incubation with the following primary antibodies was performed overnight at $4^{\circ} \mathrm{C}$ : Rabbit anti-human FOXM1 polyclonal antibody (cat.no. sc-502; 1:1,000; Santa Cruz Biotechnology, Inc.) mouse anti-human Cdk2 monoclonal antibody (cat. no. sc-6248; 1:1,000; Santa Cruz Biotechnology, Inc.), rabbit anti-human cyclin E polyclonal antibody (cat. no. 07-687; 1:1,000; Sigma-Aldrich; Merck KGaA), mouse anti-human monoclonal antibodies against $\beta$-actin (cat. no. MAB1501; 1:8,000; Sigma-Aldrich; Merck KGaA) and GAPDH (cat. no. MAB374; 1:8,000; Sigma-Aldrich; Merck KGaA) and rabbit anti-human cyclin D1 monoclonal antibody (cat. no. EPR2241; 1:1,000; Epitomics; Abcam). Following primary antibody incubation, membranes were incubated with the following secondary antibodies for $1 \mathrm{~h}$ at room temperature: Peroxidase-conjugated goat anti-mouse immunoglobulin G (IgG; cat. no. AP124P; 1:5,000; Sigma-Aldrich; Merck KGaA) and peroxidase-conjugated goat anti-rabbit IgG (cat. no. AP132P; 1:5,000; Sigma-Aldrich; Merck KGaA). Protein bands were visualized using Immobilon Western Chemiluminescent HRP substrate (cat. no. WBKLS0500; Millipore; Merck KGaA). Quantification was performed using Image Gauge v3.46 (Fujifilm Holdings Corporation) and relative expression was normalized to b-actin or GAPDH expression.

Dual-luciferase reporter assay. To clone the FOXM1 5'-flanking region for the promoter activity assay, fragments of the FOXM1 promoter (positions -1560 to +22 ) were amplified with the respective forward (5'-CCGGGTACCTCTCTTCCTCTCTCTCTC TCC-3') and reverse (5'-CCGCTCGAGCAGTTTGTTCCGCTG TTTG-3') primers based on the published nucleotide sequence (GenBank accession no. NT009759) and cloned into a pGL3-Basic vector (Promega Corporation). Two negative TRE (nTRE) motifs, NM23H1 and hTSH $\beta-\mathrm{N}$, were applied to Vector NTI advance 11 software (Invitrogen; Thermo Fisher Scientific, Inc.) for the prediction of potential nTREs of the FOXM1 promoter sequence. Serially-deleted FOXM1 promoter fragments were amplified using the following primers: Forward, 5'-CCGGGTACCCCAACTGTT CTGCCCTAATCCA-3' (-1480 to +22); forward, 5'-CCGGGTACC CACACCACACTCCATTCAGGTC-3' (-1300 to +22); forward 5'-CCGGGTACCCTCCAGAGTAGCTGGGACTACAGGCA-3' (-914 to +22); forward, 5'-CCGGGTACCGATTAAAATGTCTGT GCCCCTCTTCC-3' (-728 to +22) and reverse, 5'-CCGCTCGAG CAGTTTGTTCCGCTGTTTG-3'. To determine the transactiva- tion activity of the TREs on the FOXM1 promoter, HepG2-TR $\alpha 1$ cells $\left(5 \times 10^{5}\right.$ cells/24-well dish) were cultured in DMEM with $1 \%$ PS, L-glutamine, NEAAs and 10\% Td-FBS and transfected with $0.2 \mu \mathrm{g}$ pGL3-Basic vector containing FOXM1 promoter sequences using the TurboFect reagent kit. Cells were also transfected with $0.05 \mu \mathrm{g} \beta$-galactosidase expression vector, $\mathrm{pSV} \beta$ plasmid (Clontech Laboratories, Inc.). At $24 \mathrm{~h}$ after transfection, cells were treated with 0 or $10 \mathrm{nM} \mathrm{T}_{3}$ for an additional $24 \mathrm{~h}$, and were then lysed to measure luciferase and $\beta$-galactosidase activities using a Luciferase Assay System (cat. no. E1500; Promega Corporation). Luciferase activity was normalized to $\beta$-galactosidase activity.

Chromatin immunoprecipitation (ChIP) assay. HepG2-TRa1 cells $\left(4 \times 10^{6}\right)$ were cultured in DMEM with $1 \%$ PS, L-glutamine, NEAAs and $10 \%$ Td-FBS and treated with 0 or $10 \mathrm{nM} \mathrm{T}_{3} 24 \mathrm{~h}$, then cross-linked by adding $1 \%(\mathrm{v} / \mathrm{v})$ formaldehyde for $10 \mathrm{~min}$ at room temperature. The reaction was terminated by treatment with $0.125 \mathrm{M}$ glycine. Following washing with ice-cold PBS, cells were resuspended in RIPA buffer [50 mM Tris, $\mathrm{pH}$ 8.0, with $0.1 \%$ (w/v) sodium deoxycholate, $0.1 \%$ (w/v) SDS, $150 \mathrm{mM}$ $\mathrm{NaCl}$ and $5 \mathrm{mM}$ EDTA] containing protease inhibitors $(1 \mathrm{mM}$ each of PMSF, aprotinin and leupeptin). Solutions were sonicated using a Misonix Sonicator 3000 homogenizer (Mandel Scientific Company Inc.). All samples were precleared by the addition of $60 \mathrm{ml}$ protein A/G-agarose (Sigma-Aldrich; Merck $\mathrm{KGaA})$ for $1 \mathrm{~h}$ at $4^{\circ} \mathrm{C}$. Next, an anti-TR antibody $(3 \mu \mathrm{g} / \mathrm{ml})$ (provided by Dr SY Cheng, National Cancer Institute, National Institutes of Health, Bethesda, Maryland, USA) or anti-IgG antibody ( $3 \mu \mathrm{g} / \mathrm{ml}$; cat. no. MAB1101; R\&D Systems, Inc.) was added and incubation proceeded at $4^{\circ} \mathrm{C}$ overnight before the addition of $80 \mathrm{ml}$ protein $\mathrm{A} / \mathrm{G}$-agarose suspension for pulldown of relevant DNA/protein complexes. A fragment containing the predicted negative TRE (nTRE) of the FOXM1 promoter was amplified using the forward primer, 5'-CAACATTTGTTT GTTTTGGAGACGG-3' and reverse primer, 5'-AAAAATTAG CCGGGCGTGGT-3'. A fragment lacking the nTRE of GAPDH was detected using the forward primer, 5'-CAAGGCTGAGAA CGGGAAGC-3' and reverse primer 5'-AGGGGGCAGAGA TGATGACC-3', which served as a negative control.

Cell proliferation assay. The proliferative capacity of the aforementioned FOXM1 knockdown and overexpression cell lines was assessed by proliferation assay. Cells were seeded at a density of $3 \times 10^{4}$ cells/six-well plate routinely grown in DMEM with $1 \%$ PS, L-glutamine, NEAAs and 10\% FBS. Trypsin was used to isolate cells from culture plates after 1, 3 and 5 days. Cells were then resuspended in $1 \mathrm{ml}$ DMEM with $1 \%$ PS, L-glutamine, NEAAs and 10\% FBS. A total of $10 \mu 1$ cell suspension were stained with equal parts of $0.4 \%$ trypan blue, and live cells were counted using a LUNA-II ${ }^{\mathrm{TM}}$ Automated Cell Counter (Logos Biosystems). To assess the proliferatve capacity of $\mathrm{T}_{3}$-mediated FOXM1 expression, $5 \mu \mathrm{g}$ FOXM1-pcDNA3.1 (Neo-FOXM1) and $5 \mu \mathrm{g}$ control plamid pcDNA3.1 (Neo) were transfected into SK-Hep1 and Huh7 cells with TurboFect reagent for $24 \mathrm{~h}$, and cells were seeded at a density of $3 \times 10^{4}$ cells/six-well plate routinely grown in DMEM with $1 \%$ PS, L-glutamine, NEAAs and $10 \%$ Td-FBS and treated with 0 or $10 \mathrm{nM} \mathrm{T}_{3}$ for 24,72 and $120 \mathrm{~h}$ (days 1,3 and 5). Trypsin was used to isolate cells from culture plates at indicated timepoints. Cells were resuspended in $1 \mathrm{ml}$ DMEM 
A

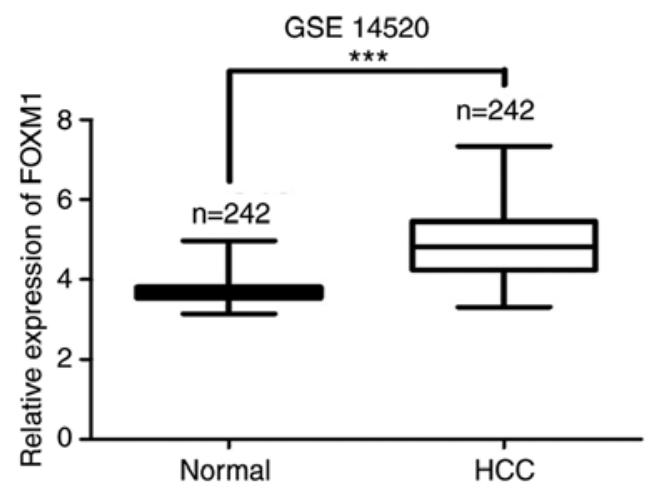

C

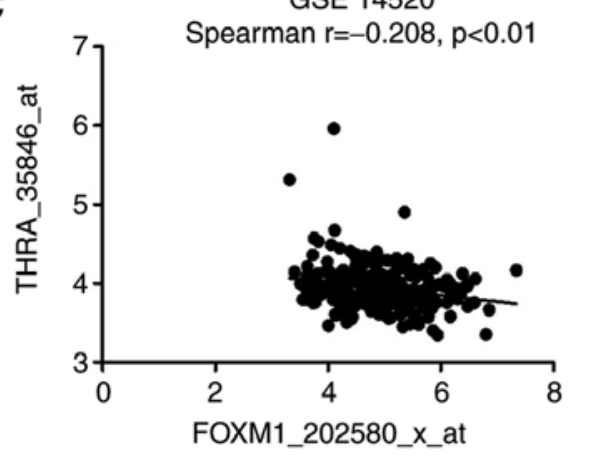

E

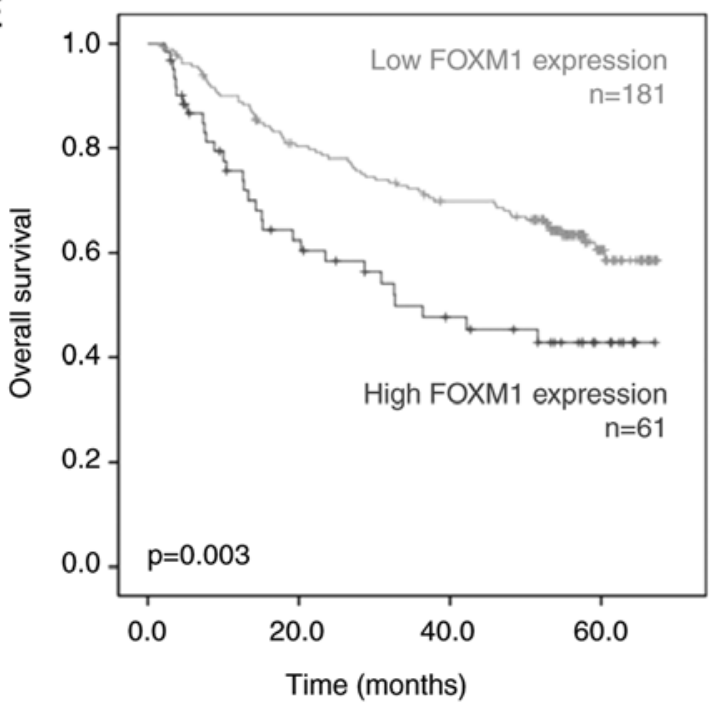

B

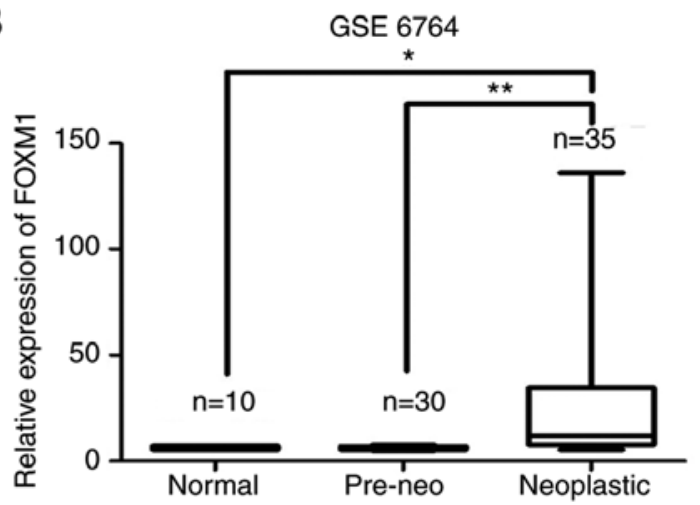

D

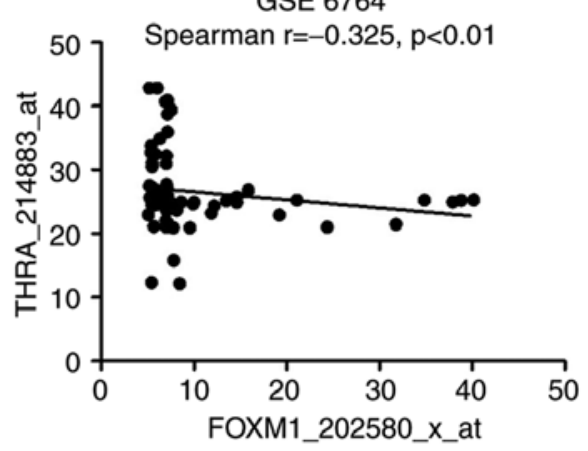

$\mathrm{F}$

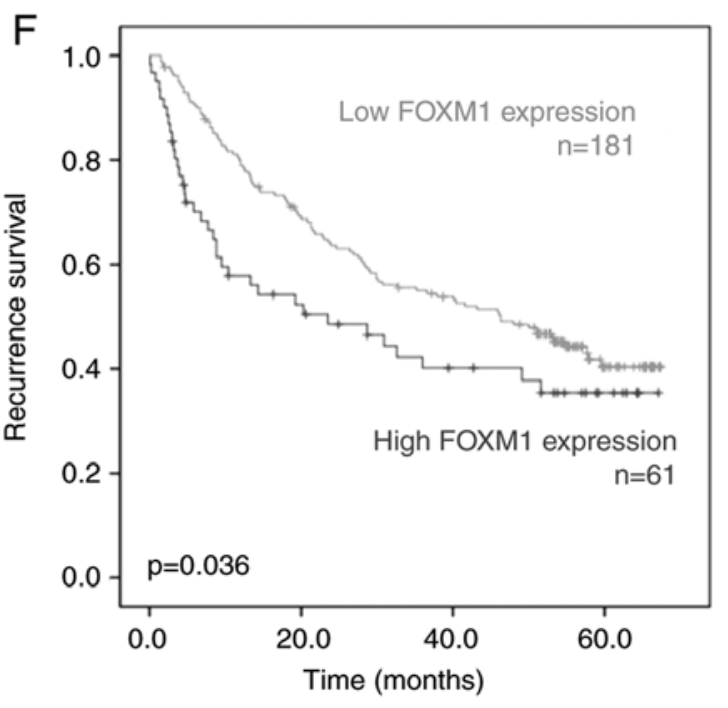

Figure 1. High expression of FOXM1 is associated with poor prognosis in HCC. Comparison of FOXM1 expression between normal and HCC tissues in two independent cohorts (A) GSE14520 and (B) GSE6764. Spearman's correlation analysis of THR $\alpha$ and FOXM1 expression in (C) GSE14520 and (D) GSE6764. (E) Kaplan-Meier survival analysis of FOXM1 in GSE14520. (F) Recurrence Kaplan-Meier survival analysis of FOXM1 in GSE14520.

with $1 \%$ PS, L-glutamine, NEAAs and $10 \%$ Td-FBS. A total of $10 \mu \mathrm{l}$ cell suspension were stained with equal parts of $0.4 \%$ trypan blue, and live cells were counted using a LUNA-II ${ }^{\mathrm{TM}}$ Automated Cell Counter (Logos Biosystems).

Bioinformatics. Public microarray data from the Gene Expression Omnibus (GEO; http://www.ncbi.nlm.nih.gov/geo) with accession numbers GSE14520 (48) (cohort 1), GSE6764 (49) (cohort 2) and GSE14323 (50) (data not shown) were analyzed. Raw gene expression data were normalized using the Robust Multi-array Average method and global median centering (51). Statistical analysis was performed using SPSS 20 (IBM Corp.).
Statistical analysis. Statistical analysis was performed using SPSS 20 (IBM Corp.). One-way ANOVA was used to compare the results obtained for more than one treatment. Data were analyzed using medians, standard deviations, one-way ANOVA and Tukey's Honest Significant Difference post hoc test. Differences between grpups with two independent variables were analyzed using two-way ANOVA and Bonferroni's post hoc test. Differences between groups were analyzed with Student's t-test. Data are presented the mean \pm SD from at least three independent experiments. Expression of FOXM1 and TR $\alpha 1$ in GSE14520 and GSE6764 were analyzed by Spearman's rank correlation. Quartile $\left(\mathrm{Q}_{3}\right)$ expression levels of FOXM1 were 
G
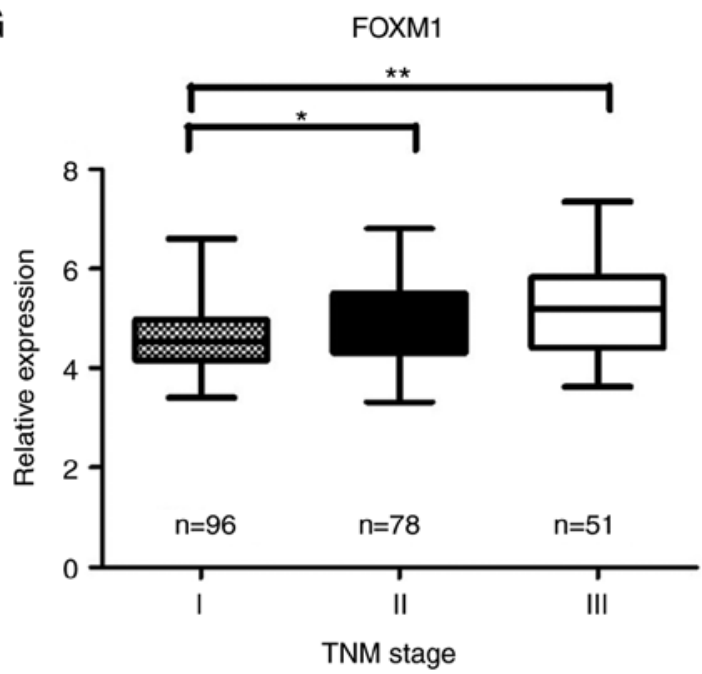

I

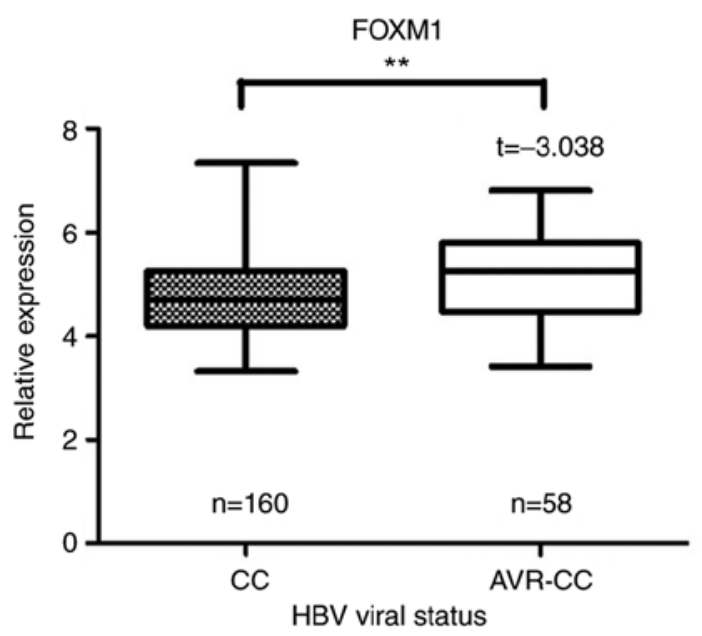

$\mathrm{H}$
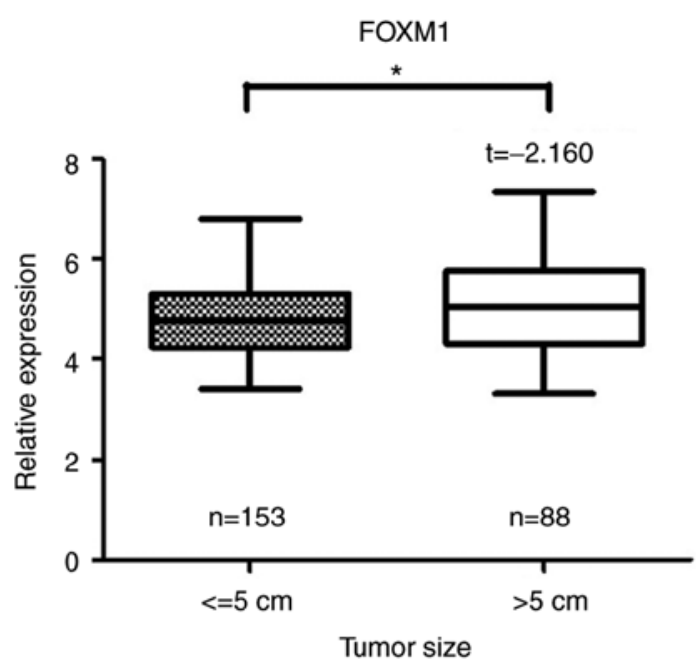

$J$

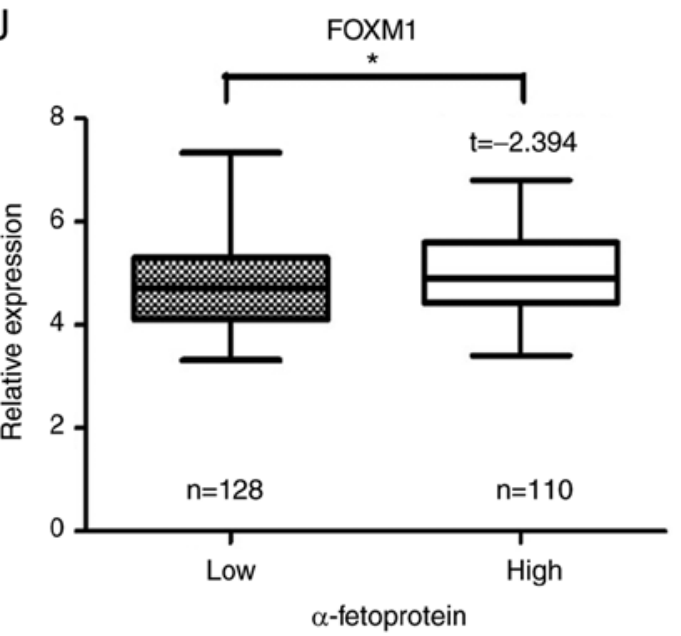

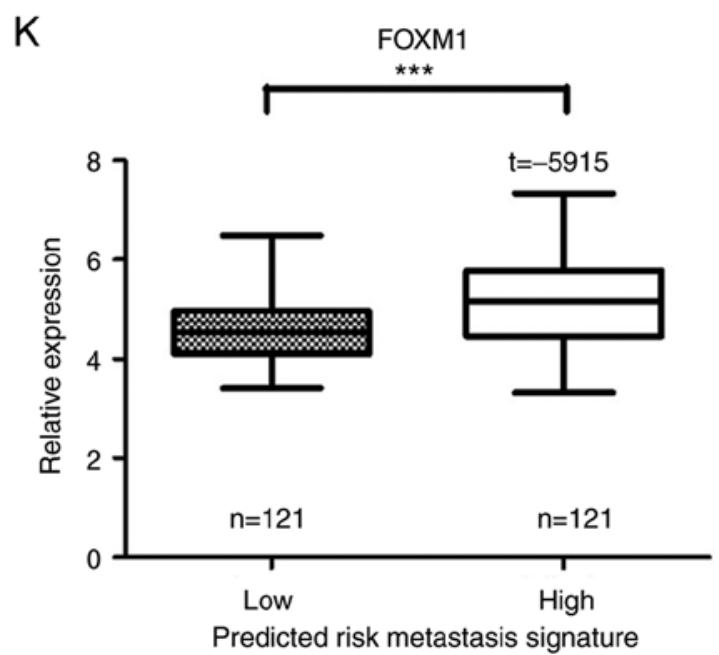

Figure 1. Continued. High expression of FOXM1 is associated with poor prognosis in HCC. (G) Expression analysis of FOXM1 with TNM staging. Analysis of clinicopathological parameters including $(\mathrm{H})$ tumor size, (I) HBV viral status, (J) alpha-fetoprotein and (K) predicted risk metastasis signature of FOXM1 in GSE14520. Data are presented as the mean \pm standard deviation. ${ }^{*} \mathrm{P}<0.05,{ }^{* *} \mathrm{P}<0.01$ and ${ }^{* * * *} \mathrm{P}<0.001$. AVR-CC, active viral replication chronic carrier; CC, chronic carrier; FOXM1, forkhead box protein M1; HCC, hepatocellular carcinoma; TNM, TNM Classification of Malignant Tumors; HBV, hepatitis B virus.

used as the cutoff, overall survival and recurrence survival were analyzed using the Kaplan-Meier survival analysis curve for high- or low-FOXM1 expression in 242-paired HCC patients of GSE14520. P-values were determined by the log-rank test. $P<0.05$ was considered to indicate a statistically significant difference.

\section{Results}

High expression of FOXM1 is associated with poor survival in HCC. FOXM1 expression was analyzed using GEO datasets, a web-based microarray database and data mining platform. 
A

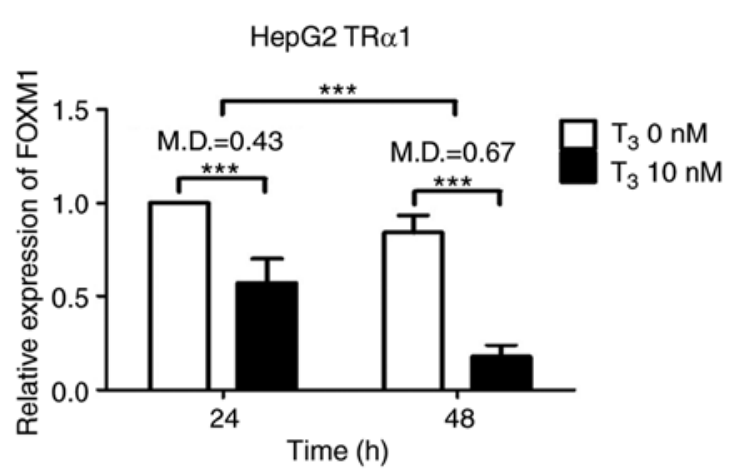

$\mathrm{B}$

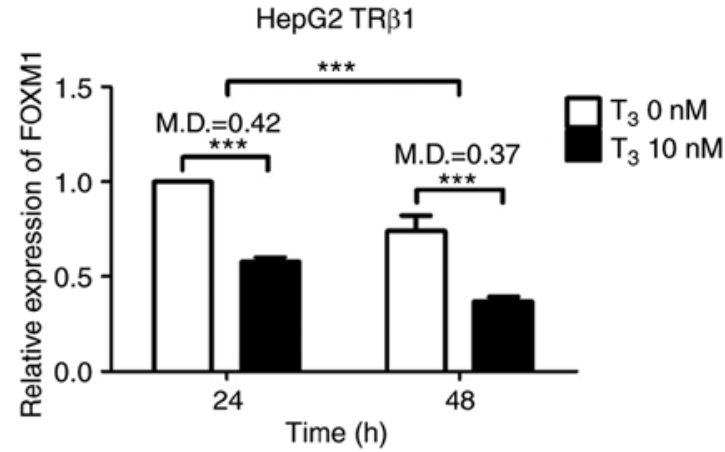

C

HepG2 Neo

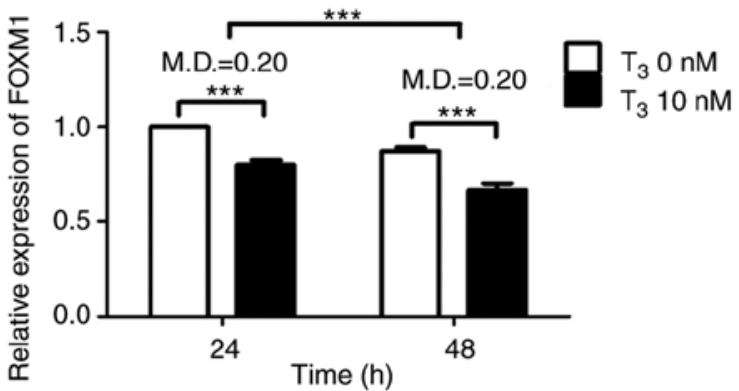

D

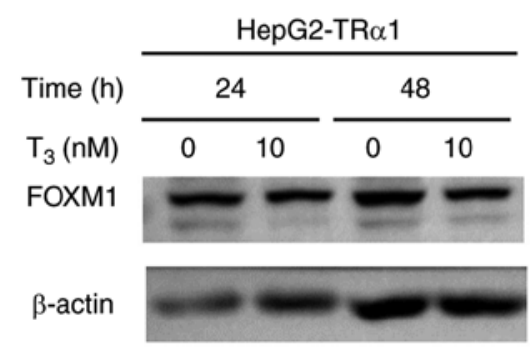

$\mathrm{E}$

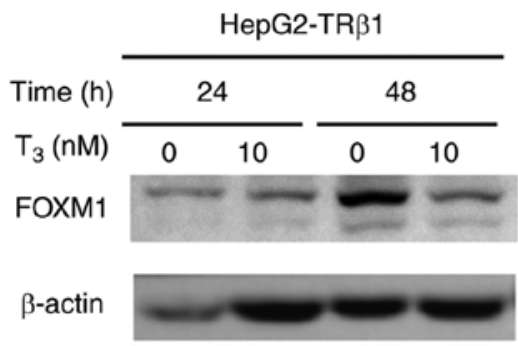

$\mathrm{F}$

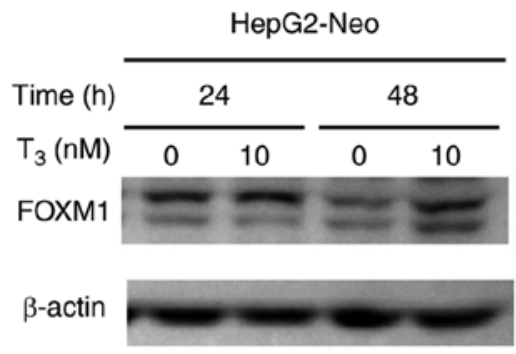

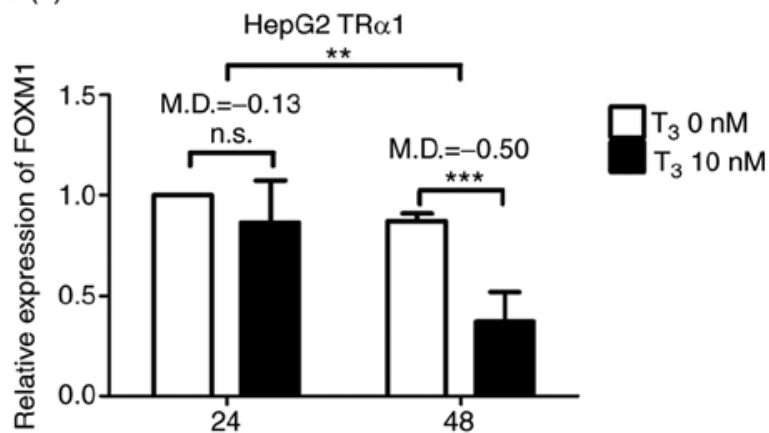

HepG2 TRß1
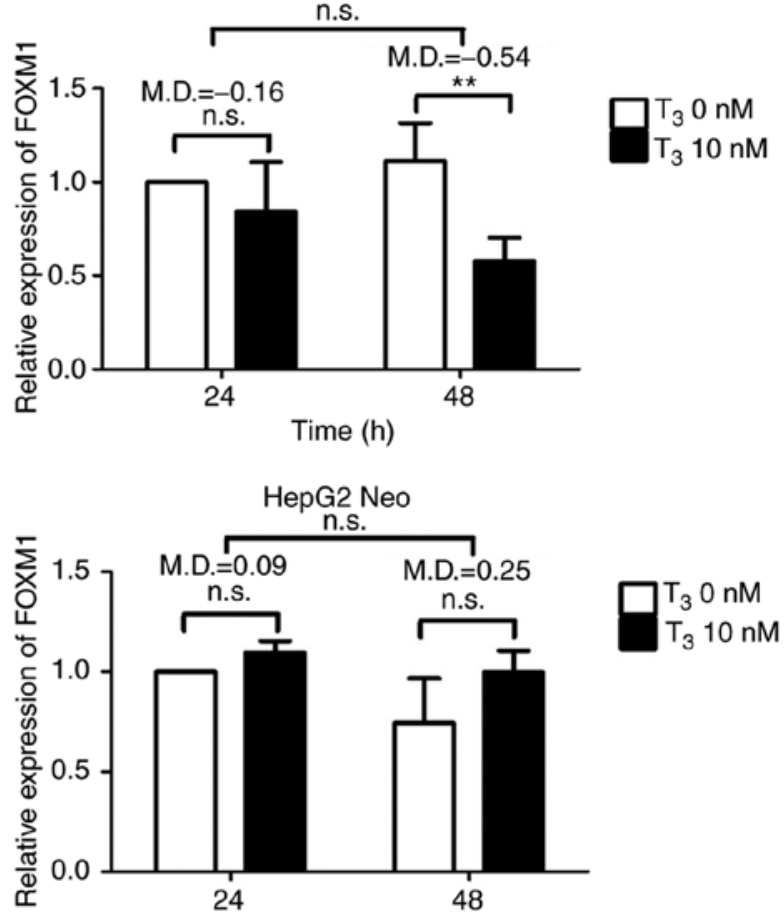

Figure 2. $\mathrm{T}_{3}$ /TR suppresses FOXM1 expression in HepG2 cells. Analysis of FOXM1 mRNA expression in (A) HepG2-TR $\alpha 1$, (B) HepG2-TR 31 and (C) HepG2-Neo cells after treatment with 0 and $10 \mathrm{nM} \mathrm{T}_{3}$ for 24 and 48 h. Protein expression of FOXM1 was analyzed in (D) HepG2-TR $\alpha 1$, (E) HepG2-TR $\beta 1$ and (F) HepG2-Neo cells after treatment with 0 and $10 \mathrm{nM} \mathrm{T}_{3}$ for 24 and $48 \mathrm{~h}$. Quantitative results are shown at the right panel. 
G
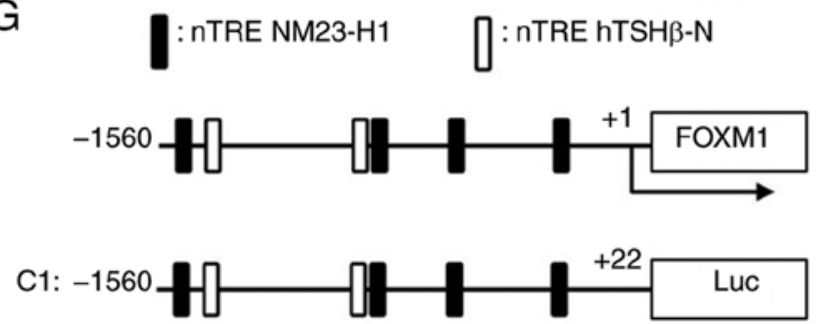

$\mathrm{H}$
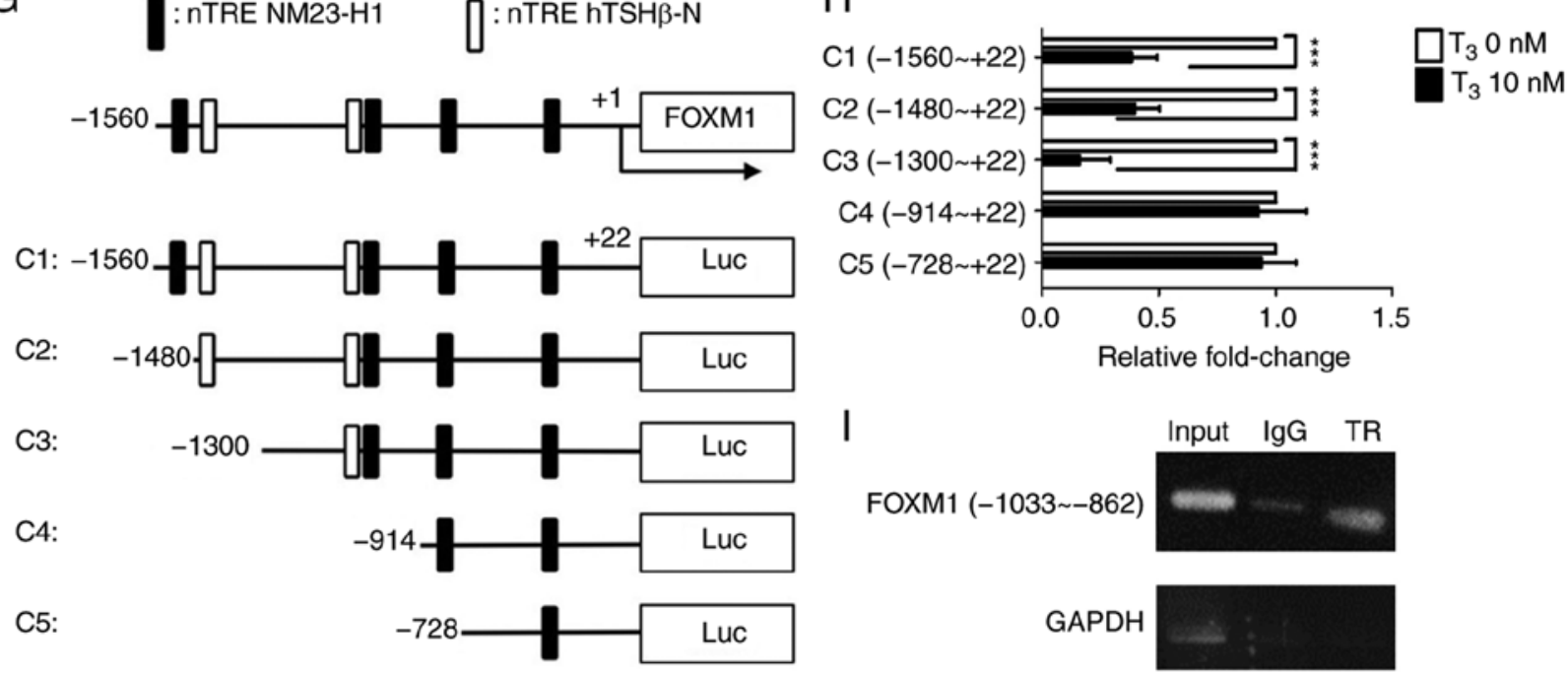

Figure 2. Continued. $\mathrm{T}_{3} / \mathrm{TR}$ suppresses FOXM1 expression in HepG2 cells. (G) Illustration of predicted nTREs within the FOXM1 promoter region. (H) Reporter constructs containing serially deleted fragments of the FOXM1 5'-flanking region in a pGL3-luc vector were transfected into HepG2-TR $\alpha 1$ cells treated with or without $10 \mathrm{nM} \mathrm{T}_{3}$. (I) For the chromatin immunoprecipitation assay, HepG2-TR $\alpha 1$ cell lysates were immunoprecipitated with rabbit nonspecific IgG or antibodies against TR. The promoter region of GAPDH acted as the negative control. Data are presented as the mean \pm standard deviation. $\mathrm{n}=3$. ${ }^{* *} \mathrm{P}<0.01$ and ${ }^{* * *} \mathrm{P}<0.001$. MD, mean of difference; FOXM1, forkhead box protein M1; TR, thyroid hormone receptors; nTRE, negative thyroid hormone response elements; ns, not significant; IgG, immunoglobulin G; C1, -1560 +22; C2, -1480 +22; C3, -1300 +22); C4, -914 +22); C5, -728 +22, Luc, pGL3-Basic vector containing serially deleted FOXM1 promoter fragments.

Analysis of three independent cohorts revealed significantly higher expression of FOXM1 mRNA in tumor regions of patients compared with normal tissues (Fig. 1A and B). Signifciantly decreased FOXM1 mRNA was accompanied by a concomitant increase in THRA (Fig. 1C and D) in cohort 1 and cohort 2. Although FOXM1 mRNA expression is inversely correlated with THRA mRNA expression, there was no significant difference of FOXM1 mRNA expression between tumor regions and normal tissues of patients in GSE14323 (data not shown). Further analysis of GSE14520 indicated that FOXM1 expression is negatively associated with overall survival (Fig. 1E) and recurrence survival (Fig. 1F). Significantly increased FOXM1 expression was detected at the late stages of HCC (Fig. 1gG and positively associated with specific clinicopathological parameters, including tumor size (Fig. 1H), hepatitis V viral status (Fig. 1I), alpha fetoprotein (Fig. 1J) and predicted metastasis risk signatures (Fig. 1K).

TH inhibits FOXM1 mRNA and protein levels in HCC cells. To determine the potential significance of $\mathrm{T}_{3} / \mathrm{TR}$ in modulating FOXM1, HepG2-TR $\alpha 1$, HepG2-TR $\beta 1$ and HepG2-Neo (vector-control) cell lines previously established in our laboratory were used for experiments (46). FOXM1 mRNA was quantified after $\mathrm{T}_{3}$ treatment of cells via RT-qPCR. In the presence of $\mathrm{T}_{3}$, compared with controls, FOXM1 mRNA expression was significantly decreased in HepG2-TR $\alpha 1$ (Fig. 2A) and HepG2-TR $\beta 1$ (Fig. 2B) cells but less reduced in HepG2-Neo cells (Fig. 2C). Western blot analysis further demonstrated a significant decrease in FOXM1 protein expression in HepG2-TR $\alpha 1$ (Fig. 2D) and HepG2-TR $\beta 1$ (Fig. 2E) cells following treatment with $\mathrm{T}_{3}$ for $48 \mathrm{~h}$ but not in HepG2-Neo cells (Fig. 2F). To ascertain whether $\mathrm{T}_{3}$-induced repression of FOXM1 mRNA in HepG2 cells is mediated by direct effects of TR on transcription, the promoter region of FOXM1 with two nTRE motifs, NM23H1 and hTSH $\beta-\mathrm{N}$, was analyzed. Several potential nTREs were identified in FOXM1 promoter regions from positions -1560 to +22 (Fig. 2G). Subsequently, serially-deleted FOXM1 promoter fragments were cloned into a pGL3-Basic vector. The promoter activity of FOXM1 was significantly repressed in fragments encompassing positions -1560 to $+22,-1480$ to +22 and -1300 to +22 with $\mathrm{T}_{3}$ treatment compared with controls. However, the effects of $\mathrm{T}_{3}$ were reduced in fragments -914 to +22 and -728 to +22 (Fig. $2 \mathrm{H}$ ). Data from ChIP performed to validate the potential binding site of TR suggested that $\mathrm{T}_{3}$ mediated suppression of FOXM1 promoter activity, with the promoter binding site of TR potentially located between positions -1033 and -862 (Fig. 2I). This indicated that $\mathrm{T}_{3}$ suppressed both FOXM1 mRNA and protein expression in a concentration- and time-dependent manner, which is positively associated with TR expression.

Manipulation of FOXM1 expression in HCC cell lines affects cell proliferation. To ascertain whether FOXM1 participates in liver cancer progression, the present study established stable J7 and Mahlavu cells with shRNA-mediated FOXM1 knockdown (shFOXM1\#1 and shFOXM1\#2) and overexpression in SK-Hep1 cells via transient transfection of control pcDNA3.1 vector (Neo\#1 and Neo\#2) and pcDNA3.1-FOXM1 (FOXM1\#1 and FOXM1\#2). Depletion of FOXM1 led to significantly reduced growth of both cell lines at day 5 (Fig. 3A and B) compared with their respective controls (shluc\#1 and shluc\#2). Conversely, overexpression of FOXM1 induced a significant increase in the cell growth rate (Fig. 3C) compared with the vector-transfected control group. The signal transduction pathway associated with alterations in FOXM1 expression were additionally investigated. Depletion of FOXM1 led to significantly reduced expression of positive regulators of cell cycle progression (cyclin D1, cyclin E and CDK2) in both J7 
A

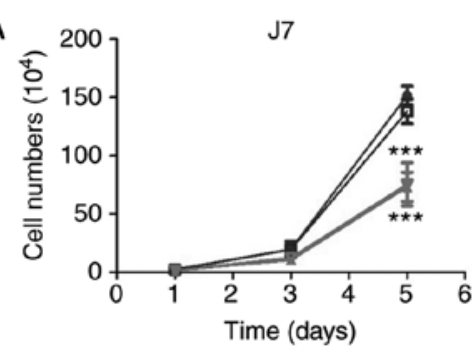

B

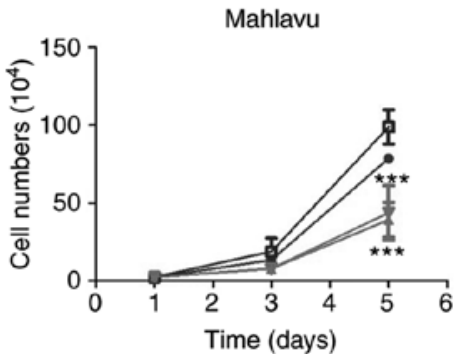

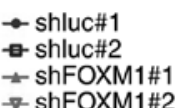

$\rightarrow$ shluc\#1

- ShFOXM1\#1

$\rightarrow$ ShFOXM1\#2

C
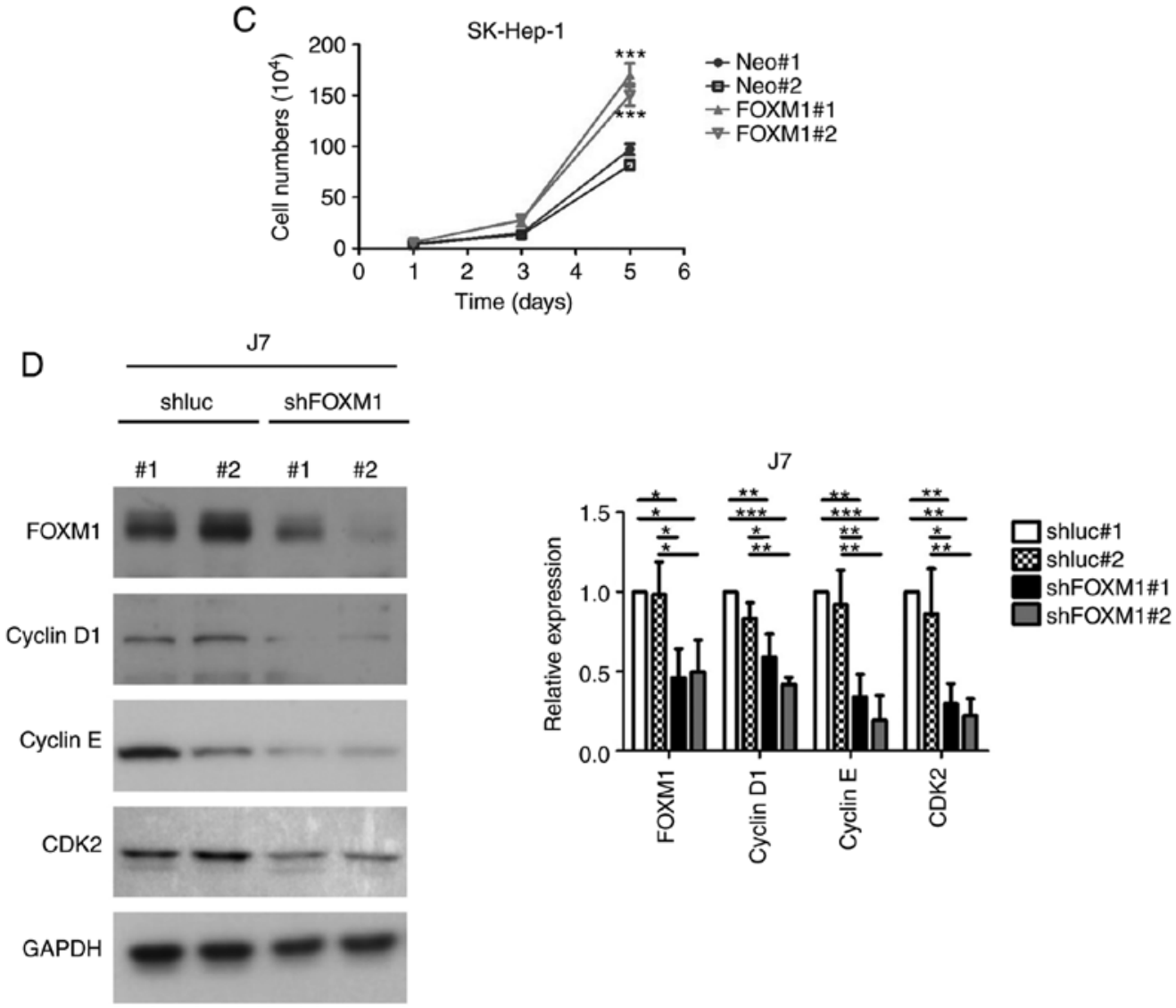

Figure 3. Manipulation of FOXM1 expression affects the proliferation rate of hepatocellular carcinoma cell lines. FOXM1 knockdown (shFOXM1\#1 and shFOXM1\#2) and control (shluc\#1 and shluc\#2) (A) J7 or (B) Mahlavu cells were seeded in six-well plates (3x104 cells) and counted at the indicated times (days 1, 3 and 5). (C) SK-Hep1 cells transfected with pcDNA3.1 vector control (Neo\#1 and Neo\#2) and pcDNA3.1-FOXM1 (FOXM1\#1 and FOXM1\#2) were

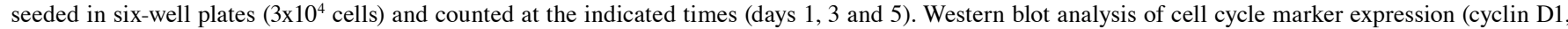
cyclin $\mathrm{E}$ and $\mathrm{CDK} 2)$ in (D) $\mathrm{J} 7$.

(Fig. 3D) and Mahlavu cells (Fig. 3E) compared with their respective controls. Consistent with these findings, enhanced expression of FOXM1 significantly increased the levels of cell cycle-promoting cyclin D1, cyclin E and CDK2 (Fig. 3F). These results collectively demonstrated a tumor-promoting role of FOXM1 in HCC cells, highlighting the role of $\mathrm{T}_{3}$-mediated regulation of FOXM1 in liver cancer.

Overexpression of FOXM1 in HCC cells leads to partial recovery of response to $T_{3}$ treatment. The suppressive effect of $\mathrm{T}_{3}$ on cell proliferation rate was demonstrated in a previous study by our group (46). To determine whether $\mathrm{T}_{3}$-mediated FOXM1 decline regulates cancer progression, FOXM1 was overexpressed in Huh7 and SK-Hep-1 cells subjected to $\mathrm{T}_{3}$ treatment. Expression of FOXM1 was marginally decreased upon $\mathrm{T}_{3}$ treatment due to low expression of endogenous TR
(Fig. 4A and B). The cell proliferation rate significantly decreased in Huh7 and SK-Hep1 cells (Neo) after $\mathrm{T}_{3}$ treatment compared with controls. Re-expression of FOXM1 in Huh7 and SK-Hep1 cells (Neo-FOXM1) partially rescued suppression of cell proliferation induced by $\mathrm{T}_{3}$ (Fig. 4C and D), supporting its role in $\mathrm{T}_{3}$-mediated regulation of cell proliferation (Fig. 4E).

\section{Discussion}

Homeostasis of TH/TR signaling is critical for life processes via regulation of various downstream genes, and disruption of this fine-tuning can lead to malignancies (8). The liver has been identified as one of the targets of TR, with alterations in TH levels shown to trigger HCC (3). However, the underlying mechanisms remain to be elucidated. 
E

\begin{tabular}{l} 
Mahlavu \\
\hline shluc
\end{tabular}$\frac{\text { shFOXM1 }}{\# 1 \quad \# 2 \quad \text { \#2 }}$

FOXM1
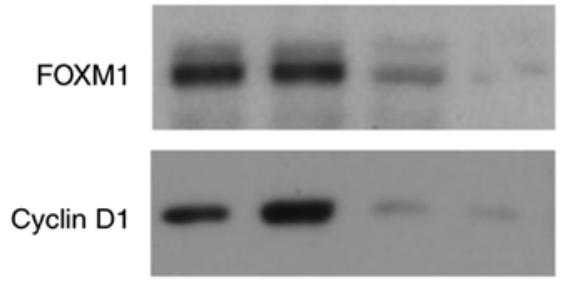

Cyclin E

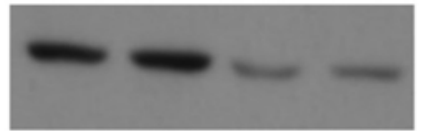

CDK2

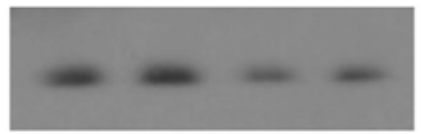

GAPDH

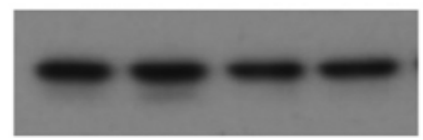

F

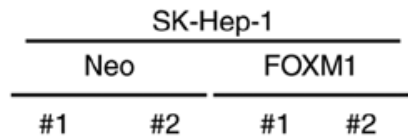

FOXM1

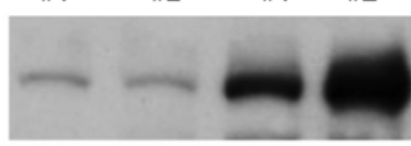

Cyclin D1

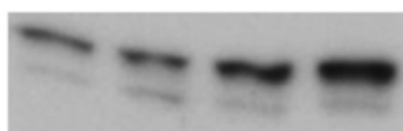

Cyclin $\mathrm{E}$

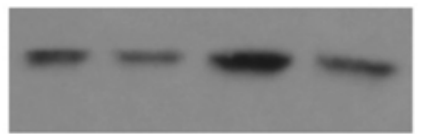

CDK2

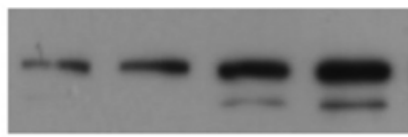

GAPDH
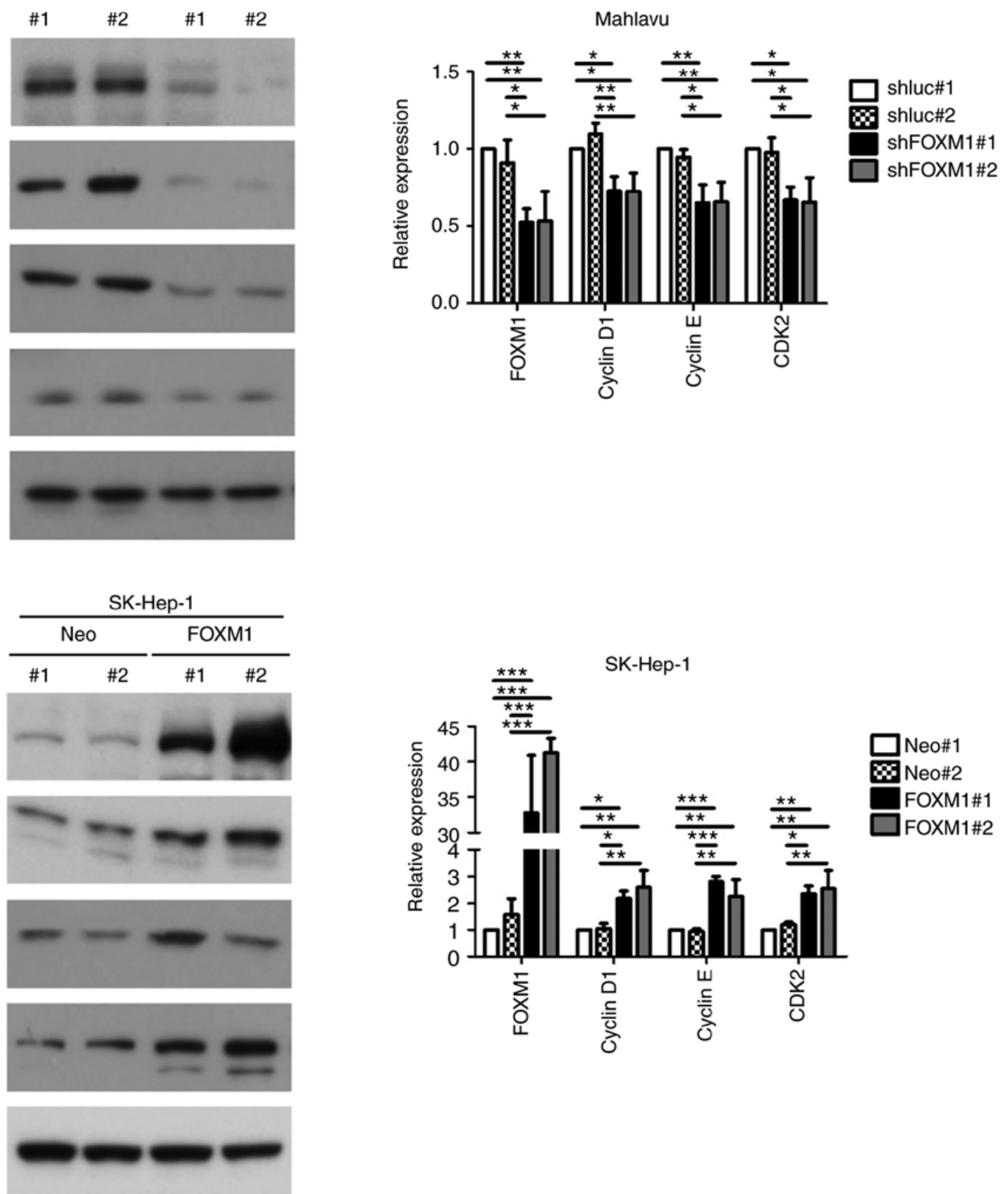

Figure 3. Continued. Manipulation of FOXM1 expression affects the proliferation rate of hepatocellular carcinoma cell lines. Western blot analysis of cell cycle marker expression (cyclin D1, cyclin E and CDK2) in (E) Mahlavu and (F) SK-Hep-1 cells. Quantitative results are shown at the right panel. Data are presented as the mean \pm standard deviation. $n=3 .{ }^{*} \mathrm{P}<0.05,{ }^{* *} \mathrm{P}<0.01$ and ${ }^{* * * *} \mathrm{P}<0.001$. FOXM1, forkhead box protein $\mathrm{M} 1$; sh, short hairpin RNA.

FOXM1 is highly expressed in several cancer types, including lung, ovarian, gastric and liver cancer (52). Data from the present study showed that TH/TR inhibited FOXM1 expression in HCC cell lines and FOXM1 and TR are negatively correlated in HCC, providing evidence supporting a tumor suppressor role of thyroid hormone signaling. A promoting role of FOXM1 in HCC development was reported by Kalinichenko et al (39), where depletion of FOXM1 had little effect in normal hepatocytes but suppressed HCC progression in a diethylnitrosamine (DEN)/phenobarbital (PB)-induced HCC mouse model, and depletion of FOXM1 following $\mathrm{HCC}$ establishment led to a significant decrease in tumor size. Park et al (42) further reported FOXM1 overexpression in the absence of p19Arf, a potent inhibitor of FOXM1. The researchers generated a bi-transgenic strain in which FOXM1 was expressed from the Rosa26 promoter in an Arf-/- (FOXM1bTg; Arf-/-) background. Mice developed highly metastatic HCC $(>70 \%)$ following DEN/PB treatment. Metastasis significantly declined in the presence of one copy of Arf (FOXM1bTg; Arft/mice), supporting a critical role of FOXM1 in HCC development and its potential application as a therapeutic target. 
A

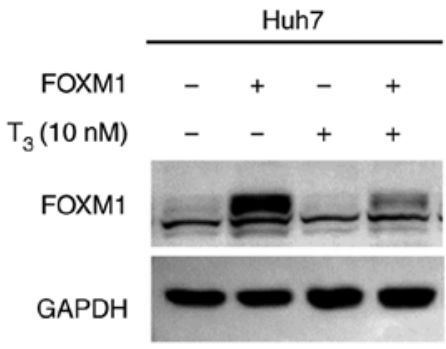

B

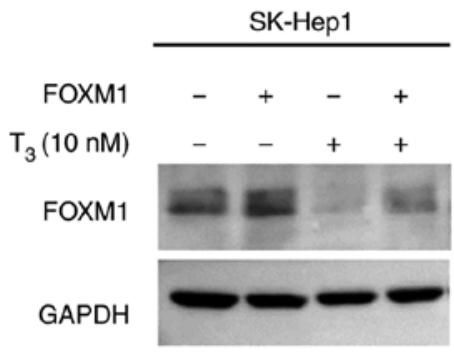

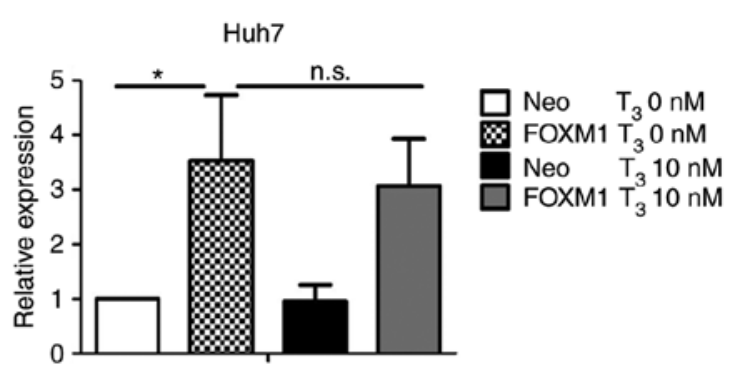

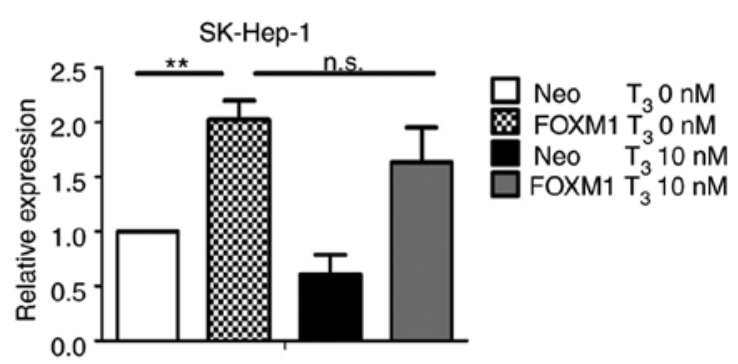

C
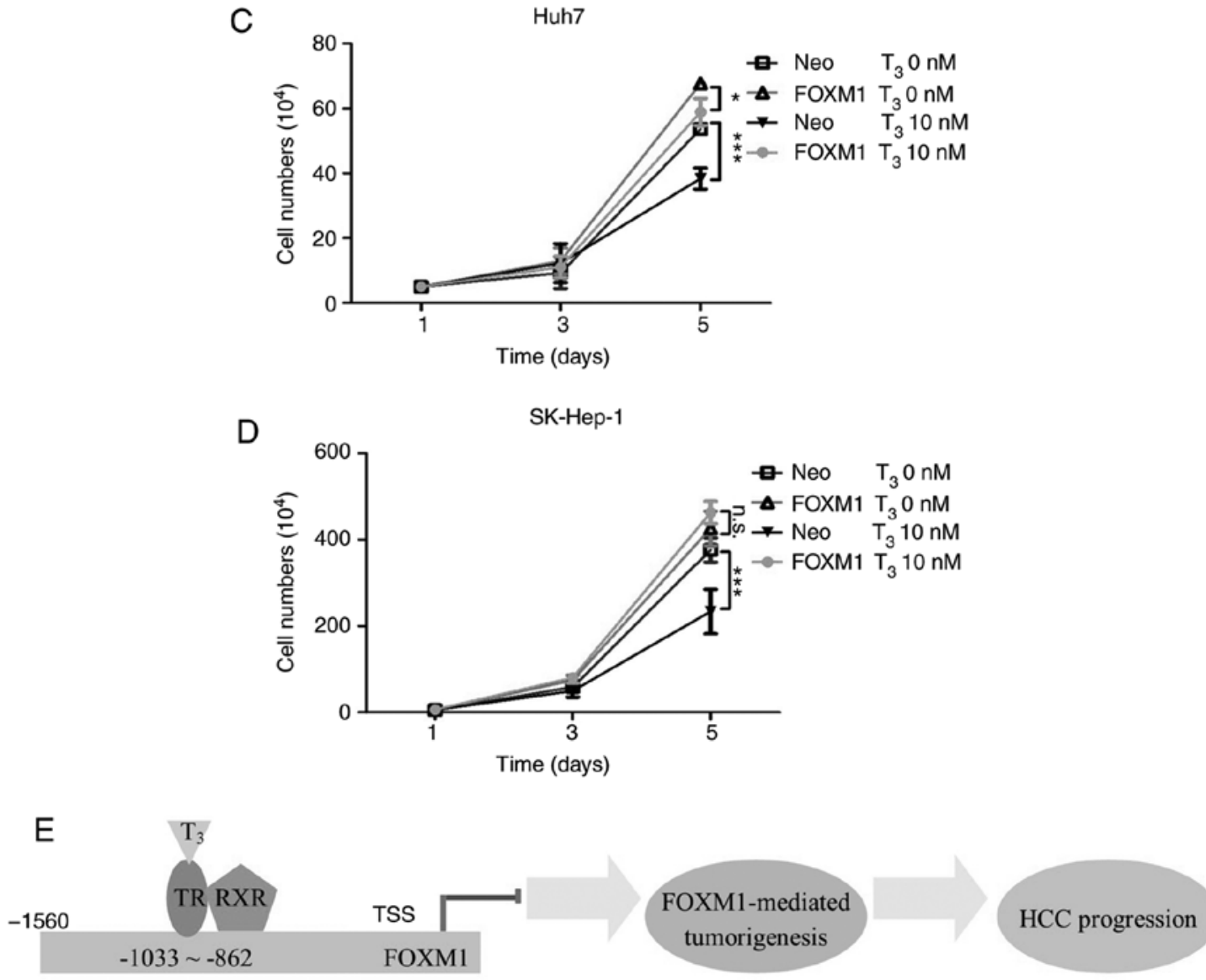

Figure 4. Overexpression of FOXM1 in HCC cells partially rescues suppression of proliferation induced by $\mathrm{T}_{3}$. FOXM1 expression in (A) Huh7 and (B) SK-Hep-1 control cells (Neo) or FOXM1-overexpressing cells (FOXM1) with $\mathrm{T}_{3}$ depletion (Neo $\mathrm{T}_{3} 0 \mathrm{nM}, \mathrm{FOXM} 1 \mathrm{~T}_{3} 0 \mathrm{nM}$ ) or $10 \mathrm{nM} \mathrm{T}$ (Neo $\mathrm{T}_{3} 10 \mathrm{nM}$, FOXM1 $\mathrm{T}_{3} 10 \mathrm{nM}$ ) for $24 \mathrm{~h}$. Quantitative results are presented in the right panel. (C) Huh7 and (D) SK-Hep-1 Neo-Td, FOXM1-Td, Neo-T ${ }_{3}$ and FOXM1-T ${ }_{3}$ cells were seeded in six-well plates and counted at the indicated times (days 1,3 and 5). (E) Schematic diagram of the mechanism underlying thyroid hormone/TR signaling-mediated suppression of FOXM1 to reduce cancer progression. The red line indicates repression. Yellow arrows indicate promotion. Data are presented as the mean \pm standard deviation. $n=3 .{ }^{*} \mathrm{P}<0.05,{ }^{* *} \mathrm{P}<0.01$ and ${ }^{* * *} \mathrm{P}<0.001$. FOXM1, forkhead box protein M1; ns, not significant; HCC, hepatocellular carcinoma; TR, thyroid hormone receptors. RXR, Retinoid X receptor; TSS, translation start site.

CDKs and cyclins are involved in cell cycle progression. For instance, phosphorylation of retinoblastoma mediated by cyclin D/CDK4/CDK6 and cyclin E/CDK2 complexes contribute to cell cycle progression (53). Moreover, the cyclin
E/CDK2 complex is reported to activate E2F transcription factors and other cell cycle-related genes, facilitating S-phase entry (54). Development of HCC is usually based on a background of chronic hepatitis and occurs as a multistep process 
involving dysregulation of multiple cell cycle-related genes, including cyclin E (55). Investigation of the role of CDK2 in hepatocarcinogenesis in $\mathrm{Cdk} 2 \Delta$ hepa mice revealed significant reduction of tumor load following DEN treatment (56). In liver regeneration studies, Foxm1-/- hepatocytes of Alb-Cre Foxm1 $\mathrm{fl} / \mathrm{fl}$ mice displayed reduced expression of the cyclin E/CDK2 complex (57), similar to FOXM1-depleted U2OS cells. Several studies reported that the cyclin E/CDK2 complex is critical for early tumorigenesis but dispensable for advanced tumor progression, highlighting the complexity of carcinogenesis and diverse roles of FOXM1 in tumor progression.

Drug resistance is a major challenge in cancer therapy. Several reports indicated that FOXM1 contributes to chemoresistance of various human carcinomas (52). Docetaxel (DTX) is a second-line chemotherapeutic drug for non-small-cell lung carcinoma. Compared to parental A549 cells, FOXM1 expression was significantly elevated in a DTX-resistant A549 cell line, while depletion of FOXM1 promoted DTX sensitivity of these cells (58). Increasing levels of FOXM1 upregulated stathmin to mediate microtubule dynamics, leading to tumor cell escape from DTX-induced apoptosis (59).

N6-methyladenosine has been identified as the most common internal modification of eukaryotic mRNAs, although its specific functions are yet to be elucidated (60). Recently, Zhang et al (61) showed that overexpression of the m6A demethylase, $\alpha$-ketoglutarate-dependent dioxygenase alkB homolog 5 (ALKBH5), is required for proliferation and tumorigenesis of glioblastoma stem-like cells and FOXM1 nascent transcripts are demethylated by ALKBH5. This step promoted the interaction between FOXM1 pre-mRNA with HuR, thereby maintaining FOXM1 expression. ALKBH5-dependent gene expression provided insights into the pivotal role of RNA m6A methylation in cancer progression, supporting a therapeutic strategy involving targeting of RNA epigenetic modulators. In the analysis of the GSE14520 dataset (48) (data not shown), THRA mRNA expression was negatively correlated with the $\mathrm{m}^{6} \mathrm{~A}$ methyltransferase, METTL3, but positively correlated with $\mathrm{m}^{6} \mathrm{~A}$ demethylase fat-mass and obesity-associated protein (FTO) (data not shown). Additionally, FOXM1 mRNA expression was positively correlated with METTL3 and negatively correlated with FTO, suggesting the possibility that FOXM1 is regulated by TH/TR through RNA modifications (data not shown).

In conclusion, TH/TR signaling suppressed FOXM1 expression, which participated in HCC progression via exerting its effects on downstream gene expression, highlighting the biological significance of thyroid hormone homeostasis in maintenance of physiological cell functions.

\section{Acknowledgements}

We greatly appreciate the valuable work carried out by Professor Sheng-Ming Wu at Taipei Medical University (New Taipei City, Taiwan) for candidate selection and primary validation.

\section{Funding}

This work was supported by grants from Chang Gung Memorial Hospital, Taoyuan, Taiwan (grant nos. CMRPD1G0421,
CMRPD1G0422, CMRPD1G0423, NMRPD1G0941, NMRPD1G0942, NMRPD1G0951 and NMRPD1G0952) and from the Ministry of Science and Technology of the Republic of China (grant nos. 106-2320-B-182-031-MY3 and 106-2320-B-182-032-MY3).

\section{Availability of data and materials}

The datasets used and/or analyzed during the current study are available from the corresponding author on reasonable request.

\section{Authors' contributions}

CHW designed the study, performed the experiments, analyzed the data and wrote the manuscript. CTY analyzed and interpreted the data. KHL designed the study, analyzed the data, critically revised the manuscript and gave final approval of the version to be published. All authors read and approved the final manuscript and agree to be accountable for all aspects of the research in ensuring that the accuracy or integrity of any part of the work are appropriately investigated and resolved.

\section{Ethics approval and consent to participate}

Not applicable.

\section{Patient consent for publication}

Not applicable.

\section{Competing interests}

The authors declare that they have no competing interests.

\section{References}

1. Wu SM, Cheng WL, Lin CD and Lin KH: Thyroid hormone actions in liver cancer. Cell Mol Life Sci 70: 1915-1936, 2013.

2. Chi HC, Chen CY, Tsai MM, Tsai CY and Lin KH: Molecular functions of thyroid hormones and their clinical significance in liver-related diseases. Biomed Res Int 2013: 601361, 2013.

3. Liu YC, Yeh CT and Lin KH: Molecular functions of thyroid hormone signaling in regulation of cancer progression and anti-apoptosis. Int J Mol Sci 20: 4986, 2019.

4. Sap J, Muñoz A, Damm K, Goldberg Y, Ghysdael J, Leutz A, Beug $\mathrm{H}$ and Vennström B: The c-erb-A protein is a high-affinity receptor for thyroid hormone. Nature 324: 635-640, 1986.

5. Weinberger C, Thompson CC, Ong ES, Lebo R, Gruol DJ and Evans RM: The c-erb-A gene encodes a thyroid hormone receptor. Nature 324: 641-646, 1986.

6. Hammes SR and Davis PJ: Overlapping nongenomic and genomic actions of thyroid hormone and steroids. Best Pract Res Clin Endocrinol Metab 29: 581-593, 2015.

7. Davis PJ, Glinsky GV, Lin HY and Mousa SA: Actions of thyroid hormone analogues on chemokines. J Immunol Res 2016: 3147671, 2016.

8. Huang PS, Wang CS, Yeh CT and Lin KH: Roles of thyroid hormone-associated microRNAs affecting oxidative stress in human hepatocellular carcinoma. Int J Mol Sci 20: 5220, 2019.

9. Davis PJ, Leonard JL, Lin HY, Leinung M and Mousa SA: Molecular basis of nongenomic actions of thyroid hormone. Vitam Horm 106: 67-96, 2018.

10. Iwasaki Y, Sunaga N, Tomizawa Y, Imai H, Iijima H, Yanagitani N, Horiguchi K, Yamada M and Mori M: Epigenetic inactivation of the thyroid hormone receptor betal gene at $3 \mathrm{p} 24.2$ in lung cancer. Ann Surg Oncol 17: 2222-2228, 2010. 
11. Liu R, Li Z, Bai S, Zhang H, Tang M, Lei Y, Chen L, Liang S, Zhao YL, Wei Y and Huang C: Mechanism of cancer cell adaptation to metabolic stress: Proteomics identification of a novel thyroid hormone-mediated gastric carcinogenic signaling pathway. Mol Cell Proteomics 8: 70-85, 2009.

12. Brown AR, Simmen RC and Simmen FA: The role of thyroid hormone signaling in the prevention of digestive system cancers. Int J Mol Sci 14: 16240-16257, 2013.

13. Davis PJ, Lin HY, Hercbergs AA, Keating KA and Mousa SA: How thyroid hormone works depends upon cell type, receptor type, and hormone analogue: Implications in cancer growth Discov Med 27: 111-117, 2019.

14. Davis PJ, Sudha T, Lin HY and Mousa SA: Thyroid hormone, hormone analogs, and angiogenesis. Compr Physiol 6: 353-362, 2015.

15. Cicatiello AG, Ambrosio R and Dentice M: Thyroid hormone promotes differentiation of colon cancer stem cells. Mol Cell Endocrinol 459: 84-89, 2017.

16. Lin HY, Chin YT, Yang YC, Lai HY, Wang-Peng J, Liu LF, Tang HY and Davis PJ: Thyroid hormone, cancer, and apoptosis Compr Physiol 6: 1221-1237, 2016.

17. Rostkowska O, Spychalski P, Dobrzycka M, Wilczyński M, Łachiński AJ, Obołończyk Ł, Sworczak K and Kobiela J: Effects of thyroid hormone imbalance on colorectal cancer carcinogenesis and risk-a systematic review. Endokrynol Pol 70: 190-197, 2019.

18. Hercbergs A, Mousa SA, Leinung M, Lin HY and Davis PJ: Thyroid hormone in the clinic and breast cancer. Horm Cancer 9 : $139-143,2018$

19. Lin $\mathrm{YH}, \mathrm{Wu} \mathrm{MH}$, Liao CJ, Huang YH, Chi HC, Wu SM, Chen CY, Tseng YH, Tsai CY, Chung IH, et al: Repression of microRNA-130b by thyroid hormone enhances cell motility. J Hepatol 62: 1328-1340, 2015.

20. Chi HC, Chen SL, Tsai CY, Chuang WY, Huang YH, Tsai MM, Wu SM,Sun CP, Yeh CT and Lin KH: Thyroid hormone suppresses hepatocarcinogenesis via DAPK2 and SQSTM1-dependent selective autophagy. Autophagy 12: 2271-2285, 2016.

21. Tseng YH, Huang YH, Lin TK, Wu SM, Chi HC, Tsai CY, Tsai MM, Lin YH, Chang WC, Chang YT, et al: Thyroid hormone suppresses expression of stathmin and associated tumor growth in hepatocellular carcinoma. Sci Rep 6: 38756, 2016.

22. Chi HC, Chen SL, Lin SL, Tsai CY, Chuang WY, Lin YH, Huang YH, Tsai MM, Yeh CT and Lin KH: Thyroid hormone protects hepatocytes from HBx-induced carcinogenesis by enhancing mitochondrial turnover. Oncogene 36: 5274-5284, 2017.

23. Puliga E, Min Q, Tao J, Zhang R, Pradhan-Sundd T, Poddar M, Singh S, Columbano A, Yu J and Monga SP: Thyroid hormone receptor- $\beta$ agonist GC- 1 inhibits met- $\beta$-catenin-driven hepatocellular cancer. Am J Pathol 187: 2473-2485, 2017.

24. Huang PS, Lin YH, Chi HC, Chen PY, Huang YH, Yeh CT, Wang CS and Lin KH: Thyroid hormone inhibits growth of hepatoma cells through induction of miR-214. Sci Rep 7: 14868, 2017.

25. Lin YH, Wu MH, Huang YH, Yeh CT, Chi HC, Tsai CY Chuang WY, Yu CJ, Chung IH, Chen CY and Lin KH: Thyroid hormone negatively regulates tumorigenesis through suppression of BC200. Endocr Relat Cancer 25: 967-979, 2018

26. Chen CY, Wu SM, Lin YH, Chi HC, Lin SL, Yeh CT, Chuang WY and Lin KH: Induction of nuclear protein-1 by thyroid hormone enhances platelet-derived growth factor A mediated angiogenesis in liver cancer. Theranostics 9: 2361-2379, 2019.

27. Kowalik MA, Puliga E, Cabras L, Sulas P, Petrelli A, Perra A Ledda-Columbano GM, Morandi $\mathrm{A}$, Merlin $\mathrm{S}$, Orrù $\mathrm{C}$, et al: Thyroid hormone inhibits hepatocellular carcinoma progression via induction of differentiation and metabolic reprogramming. J Hepatol 72: 1159-1169, 2020.

28. Chi HC, Tsai CY, Tsai MM, Yeh CT and Lin KH: Molecular functions and clinical impact of thyroid hormone-triggered autophagy in liver-related diseases. J Biomed Sci 26: 24, 2019.

29. Jemal A, Bray F, Center MM, Ferlay J, Ward E and Forman D: Global cancer statistics. CA Cancer J Clin 61: 69-90, 2011.

30. El-Serag HB and Rudolph KL: Hepatocellular carcinoma: Epidemiology and molecular carcinogenesis. Gastroenterology 132: 2557-2576, 2007.

31. Barlow C, Meister B, Lardelli M, Lendahl U and Vennström B: Thyroid abnormalities and hepatocellular carcinoma in mice transgenic for v-erbA. EMBO J 13: 4241-4250, 1994.

32. Chan IH and Privalsky ML: Thyroid hormone receptors mutated in liver cancer function as distorted antimorphs. Oncogene 25 : 3576-3588, 2006.
33. Chan IH and Privalsky ML: Thyroid hormone receptor mutants implicated in human hepatocellular carcinoma display an altered target gene repertoire. Oncogene 28: 4162-4174, 2009.

34. Lin KH, Shieh HY, Chen SL and Hsu HC: Expression of mutant thyroid hormone nuclear receptors in human hepatocellular carcinoma cells. Mol Carcinog 26: 53-61, 1999.

35. Lin $\mathrm{KH}, \mathrm{Wu} \mathrm{YH}$ and Chen SL: Impaired interaction of mutant thyroid hormone receptors associated with human hepatocellular carcinoma with transcriptional coregulators. Endocrinology 142: 653-662, 2001.

36. Lin KH, Zhu XG, Shieh HY, Hsu HC, Chen ST, McPhie P and Cheng SY: Identification of naturally occurring dominant negative mutants of thyroid hormone alpha 1 and beta 1 receptors in a human hepatocellular carcinoma cell line. Endocrinology 137: 4073-4081, 1996

37. Koo CY, Muir KW and Lam EW: FOXM1: From cancer initiation to progression and treatment. Biochim Biophys Acta 1819: 28-37, 2012

38. Lam EW, Brosens JJ, Gomes AR and Koo CY: Forkhead box proteins: Tuning forks for transcriptional harmony. Nat Rev Cancer 13: 482-495, 2013

39. Kalinichenko VV, Major ML, Wang X, Petrovic V, Kuechle J, Yoder HM, Dennewitz MB, Shin B, Datta A, Raychaudhuri P and Costa RH: Foxmlb transcription factor is essential for development of hepatocellular carcinomas and is negatively regulated by the p19ARF tumor suppressor. Genes Dev 18: 830-850, 2004

40. Shih CH, Chen SL, Yen CC, Huang YH, Chen CD, Lee YS and Lin KH: Thyroid hormone receptor-dependent transcriptional regulation of fibrinogen and coagulation proteins. Endocrinology 145: 2804-2814, 2004.

41. Bella L, Zona S, Nestal de Moraes G and Lam EW: FOXM1: A key oncofoetal transcription factor in health and disease. Semin Cancer Biol 29: 32-39, 2014.

42. Park HJ, Gusarova G, Wang Z, Carr JR, Li J, Kim KH, Qiu J, Park YD, Williamson PR, Hay N, et al: Deregulation of FoxM1b leads to tumour metastasis. EMBO Mol Med 3: 21-34, 2011.

43. Nandi D, Cheema PS, Jaiswal N and Nag A: FoxM1: Repurposing an oncogene as a biomarker. Semin Cancer Biol 52: 74-84, 2018.

44. Shiu TY, Huang TY, Huang SM, Shih YL, Chu HC, Chang WK and Hsieh TY: Nuclear factor $\kappa \mathrm{B}$ down-regulates human UDP-glucuronosyltransferase 1A1: A novel mechanism involved in inflammation-associated hyperbilirubinaemia. Biochem J 449: 761-770, 2013.

45. Chen CJ, Tsai NM, Liu YC, Ho LI, Hsieh HF, Yen CY and Harn HJ: Telomerase activity in human hepatocellular carcinoma: Parallel correlation with human telomerase reverse transcriptase (hTERT) mRNA isoform expression but not with cell cycle modulators or c-Myc expression. Eur J Surg Oncol 28: 225-234, 2002

46. Wu SM, Cheng WL, Liao CJ, Chi HC, Lin YH, Tseng YH, Tsai CY, Chen CY, Lin SL, Chen WJ, et al: Negative modulation of the epigenetic regulator, UHRF1, by thyroid hormone receptors suppresses liver cancer cell growth. Int J Cancer 137: $37-49,2015$

47. Livak KJ and Schmittgen TD: Analysis of relative gene expression data using real-time quantitative PCR and the 2(-Delta Delta C(T)) method. Methods 25: 402-408, 2001.

48. Roessler S, Jia HL, Budhu A, Forgues M, Ye QH, Lee JS, Thorgeirsson SS, Sun Z, Tang ZY, Qin LX and Wang XW: A unique metastasis gene signature enables prediction of tumor relapse in early-stage hepatocellular carcinoma patients. Cancer Res 70: 10202-10212, 2010.

49. Wurmbach E, Chen YB, Khitrov G, Zhang W, Roayaie S, Schwartz M, Fiel I, Thung S, Mazzaferro V, Bruix J, et al: Genome-wide molecular profiles of HCV-induced dysplasia and hepatocellular carcinoma. Hepatology 45: 938-947, 2007.

50. Mas VR, Maluf DG, Archer KJ, Yanek K, Kong X, Kulik L, Freise CE, Olthoff KM, Ghobrial RM, McIver P and Fisher R: Genes involved in viral carcinogenesis and tumor initiation in hepatitis $\mathrm{C}$ virus-induced hepatocellular carcinoma. Mol Med 15: 85-94, 2009.

51. Irizarry RA, Hobbs B, Collin F, Beazer-Barclay YD, Antonellis KJ, Scherf U and Speed TP: Exploration, normalization, and summaries of high density oligonucleotide array probe level data. Biostatistics 4: 249-264, 2003.

52. Borhani S and Gartel AL: FOXM1: A potential therapeutic target in human solid cancers. Expert Opin Ther Targets 24: 205-217, 2020.

53. Goel B, Tripathi N, Bhardwaj N and Jain SK: Small molecule CDK inhibitors for the therapeutic management of cancer. Curr Top Med Chem: May 162020 doi: 10.2174/15680266206662005 16152756. Online ahead of print. 
54. Kim B, Shin HC, Heo YJ, Ha SY, Jang KT, Kim ST, Kang WK, Lee $\mathrm{J}$ and Kim KM: CCNE1 amplification is associated with liver metastasis in gastric carcinoma. Pathol Res Pract 215: $152434,2019$.

55. Aziz K, Limzerwala JF, Sturmlechner I, Hurley E, Zhang C, Jeganathan KB, Nelson G, Bronk S, Fierro Velasco RO, van Deursen EJ, et al: Ccnel overexpression causes chromosome instability in liver cells and liver tumor development in mice. Gastroenterology 157: 210-226.e12, 2019.

56. Sonntag R, Giebeler N, Nevzorova YA, Bangen JM, Fahrenkamp D, Lambertz D, Haas U, Hu W, Gassler N, Cubero FJ, Müller-Newen G, et al: Cyclin E1 and cyclin-dependent kinase 2 are critical for initiation, but not for progression of hepatocellular carcinoma. Proc Natl Acad Sci USA 115: 9282-9287, 2018.

57. Wang IC, Chen YJ, Hughes D, Petrovic V, Major ML, Park HJ, Tan Y, Ackerson T and Costa RH: Forkhead box M1 regulates the transcriptional network of genes essential for mitotic progression and genes encoding the SCF (Skp2-Cks1) ubiquitin ligase. Mol Cell Biol 25: 10875-10894, 2005.
58. Wang K, Zhu X, Zhang K, Zhu L and Zhou F: FoxM1 inhibition enhances chemosensitivity of docetaxel-resistant A549 cells to docetaxel via activation of JNK/mitochondrial pathway. Acta Biochim Biophys Sin (Shanghai) 48: 804-809, 2016.

59. Li X, Yao R, Yue L, Qiu W, Qi W, Liu S, Yao Y and Liang J: FOXM1 mediates resistance to docetaxel in gastric cancer via up-regulating Stathmin. J Cell Mol Med 18: 811-823, 2014.

60. Meyer KD, Saletore Y, Zumbo P, Elemento O, Mason CE and Jaffrey SR: Comprehensive analysis of mRNA methylation reveals enrichment in 3'UTRs and near stop codons. Cell 149: 1635-1646, 2012.

61. Zhang S, Zhao BS, Zhou A, Lin K, Zheng S, Lu Z, Chen Y, Sulman EP, Xie K, Bögler O, et al: $\mathrm{m}^{6} \mathrm{~A}$ demethylase ALKBH5 maintains tumorigenicity of glioblastoma stem-like cells by sustaining FOXM1 expression and cell proliferation program. Cancer Cell 31: 591-606.e6, 2017. 